\section{RESULTS}

From 2006 to 2012, this technique was used in 15 patients, mean age 72 years, $67 \%$ female. There were no strokes, but there were 3 in-hospital deaths, none directly related to the operative technique. One patient died on postoperative day 2 of mesenteric ischemia, another on postoperative day 24 of multisystem organ failure, and the third on postoperative day 72 of severe respiratory failure.

\section{DISCUSSION}

Two groups of techniques have been described for addressing severe mitral annular calcification. The first avoids decalcification. ${ }^{2-4}$ It includes prosthesis placement-intraatrial, semi-intra-atrial, or intra-annular-after drilling holes or plicating atrial tissue and placing the prosthesis into a new annulus constructed from mitral leaflets and atrial wall. Disadvantages of intra-atrial techniques include transferring high ventricular pressure into the atrium, increasing risk of dehiscence, hemorrhage, and aneurysm formation and rupture.

Disadvantages of intra-annular techniques are the risks of paravalvar leak, valve dehiscence, and embolism from the friable calcified annulus. In addition, ability to pass sutures through the annulus depends on amount of noncalcified fibrous tissue, making these techniques less reproducible. A similar problem is encountered when placing sutures into degenerated and fragile leaflets. Consequently, this technique mandates a smaller prosthesis, which can result in prosthesis-patient mismatch.
Although intra-atrial and intra-annular techniques have been advocated as simpler alternatives to decalcification and patching, attempts to reduce risk by forming a new annulus, adding collars, plicating atrial tissue over the prostheses, and other solutions increase complexity. The quality and durability of these techniques are unknown.

The second group of $^{2,3,5}$ of techniques is characterized by excision of the calcified annulus and annular reconstruction, usually with a pericardial patch. ${ }^{1}$ The greatest concerns are that extensive débridement increases risk of atrioventricular disruption, circumflex coronary artery injury, and ventricular rupture; however, the patch increases integrity of the atrioventricular groove, lowering risk of potentially fatal complications. Nevertheless, its perceived technical complexity has limited its adoption. We find the surgical technique described to be simple, reproducible, and safe, allowing valve replacement even in patients with severe mitral annular calcification.

\section{References}

1. David TE, Feindel CM, Armstrong S, Sun Z. Reconstruction of the mitral anulus. A ten-year experience. J Thorac Cardiovasc Surg. 1995;110:1323-32.

2. Smedira NG. Mitral valve replacement with a calcified annulus. Operative Tech Thorac Cardiovasc Surg. 2003;8:2-13.

3. Mills NL, McIntosh CL, Mills LJ. Techniques for management of the calcified mitral annulus. J Card Surg. 1986;1:347-55.

4. Nataf P, Pavie A, Jault F, Bors V, Cabrol C, Gandjbakhch I. Intraatrial insertion of a mitral prosthesis in a destroyed or calcified mitral annulus. Ann Thorac Surg. 1994;58:163-7.

5. Casselman FP, Gillinov AM, McDonald ML, Cosgrove DM 3rd. Use of the anterior mitral leaflet to reinforce the posterior mitral annulus after debridement of calcium. Ann Thorac Surg. 1999;68:261-2.

\title{
Successful surgical treatment of aortoesophageal fistula after emergency thoracic endovascular aortic repair: Aggressive débridement including esophageal resection and extended aortic replacement
}

\author{
Hiroshi Munakata, MD, PhD, Katsuhiro Yamanaka, MD, Kenji Okada, MD, PhD, and Yutaka Okita, MD, PhD, \\ Kobe, Japan
}

\footnotetext{
From the Division of Cardiovascular Surgery, Department of Surgery, Kobe University Graduate School of Medicine, Kobe, Japan.

Disclosures: Authors have nothing to disclose with regard to commercial support.

Received for publication Jan 25, 2013; accepted for publication Feb 27, 2013; available ahead of print March 25, 2013.

Address for reprints: Hiroshi Munakata MD, PhD, Division of Cardiovascular Surgery, Department of Surgery, Kobe University Graduate School of Medicine, 7-5-2, Kusunoki-cho, Chuo-ku, Kobe, 650-0017 (E-mail: h-munakata@k7.dion. ne.jp).

J Thorac Cardiovasc Surg 2013;146:235-7

$0022-5223 / \$ 36.00$

Copyright (c) 2013 by The American Association for Thoracic Surgery

http://dx.doi.org/10.1016/j.jtcvs.2013.02.064
}

In recent years, thoracic endovascular aortic repair (TEVAR) has emerged as a promising, less-invasive alternative to open surgery in the treatment of aortic aneurysms and dissections ${ }^{1}$; however, some catastrophic complications do occur after TEVAR. Aortoesophageal fistula (AEF) is very rare but is associated with high mortality and morbidity. ${ }^{2}$

Here we report the successful surgical treatment of a seriously infected AEF after TEVAR. Aggressive débridement, which included the infected aortic wall, endovascular stentgrafts, and esophagus, was followed by replacement of the 

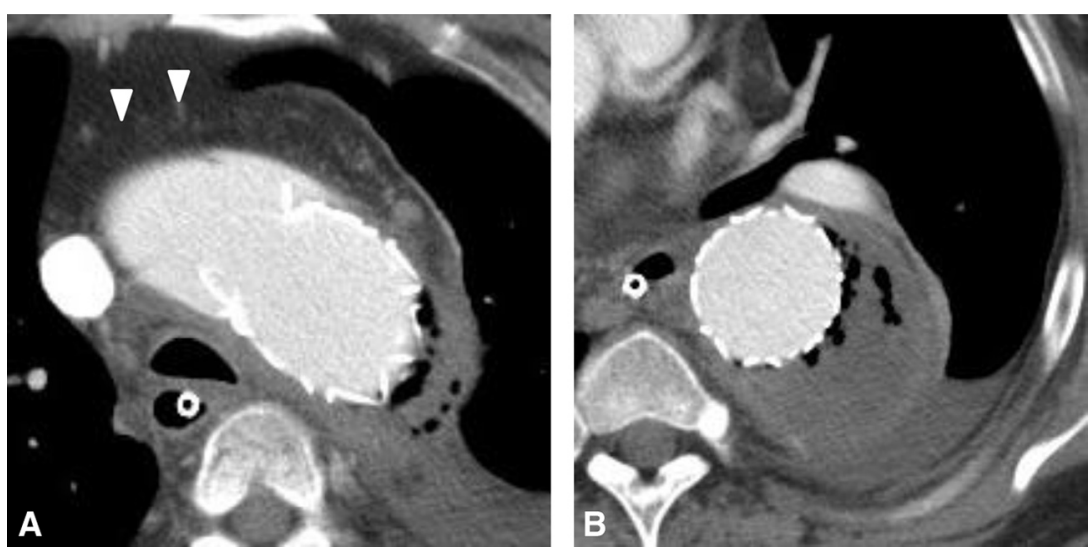

FIGURE 1. Computed tomographic images 11 weeks after endovascular stent-graft implantation. A and B, Numerous air bubbles in the extended aortic wall from the arch to the descending aorta and fluid collection around the aortic arch (A, arrows) indicate stent-graft infection caused by the aortoesophageal fistula. TEVAR, Thoracic endovascular aortic repair.

extended aorta from the proximal arch to the middle descending aorta.

\section{CLINICAL SUMMARY}

A 38-year-old man was admitted with excruciating chest pain and hemodynamic collapse. Computed tomography showed a ruptured type $\mathrm{B}$ aortic dissection with left thoracic hematoma. At another hospital, two endovascular stentgrafts (GORE TAG Thoracic Endoprosthesis; W.L. Gore, Inc, Flagstaff, Ariz), both of which were $40 \mathrm{~mm}$ in diameter and $15 \mathrm{~mm}$ in length, had been successfully deployed in the proximal descending aorta covering the ostium of the left subclavian artery. Seven weeks after TEVAR, however, stent-graft infection was suspected on the basis of pyrexia with increased levels of white blood cell counts and
C-reactive protein, and the patient was treated with intravenous antibiotics. After 11 weeks, severe hematemesis and dysphagia developed. Emergency computed tomography demonstrated numerous air bubbles around the peristent graft (Figure 1, $A$ and $B$ ) and fluid collection around the proximal aortic arch (Figure 1, A, arrows). The patient was transferred to our institution with a diagnosis of AEF.

On admission to our institution, the patient did not have hematemesis and was in hemodynamically stable condition other than a $40^{\circ} \mathrm{C}$ body temperature. He was admitted to the intensive care unit for cerebrospinal fluid drainage and transferred immediately to the operating room. A left posterolateral thoracotomy through the fourth intercostal space was performed. Intraoperative findings revealed extensive inflammation of the mediastinal tissue, as well as
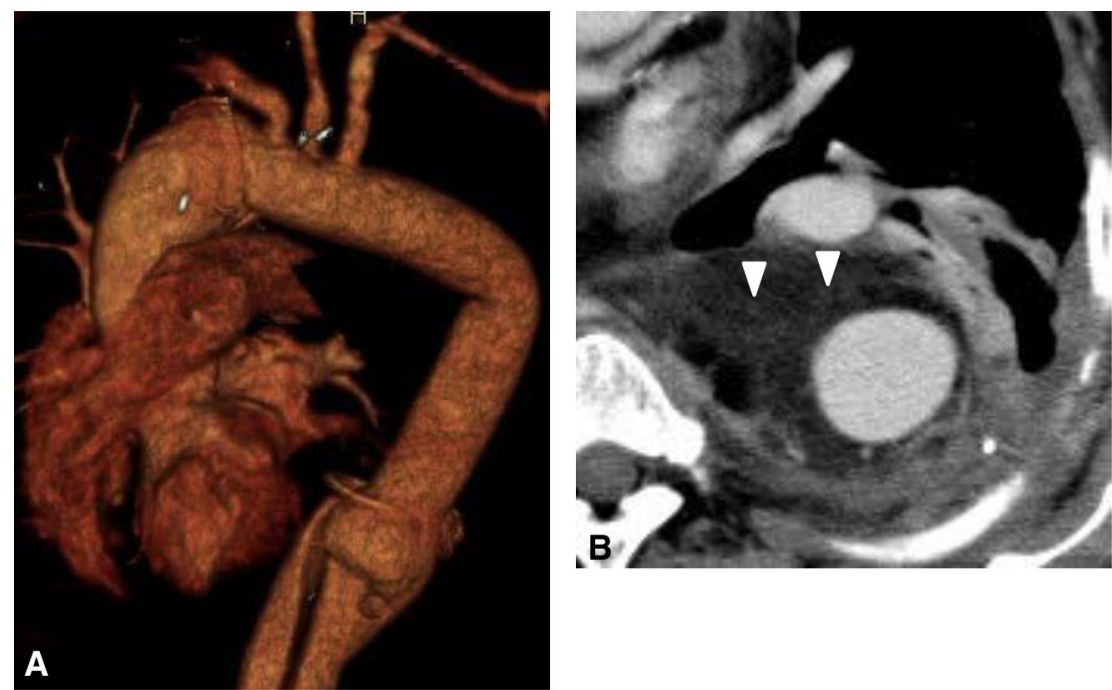

FIGURE 2. Postoperative computed tomography. A, The extended aorta from the proximal arch to the middle descending aorta has been replaced with a Dacron polyester fabric graft. B, The graft has been wrapped with a healthy omental flap (arrows). 
a malodorous abscess. The native aorta was infected from the arch to the middle descending aorta, so immediate cardiopulmonary bypass was established with the femoral artery for arterial return and the pulmonary artery for venous drainage. The patient was cooled to $28^{\circ} \mathrm{C}$ according to tympanic temperature. A distal aortic crossclamp was placed on the lower descending aorta, thereby maintaining lower body perfusion, the proximal aorta was opened, and the brain was protected by antegrade selective cerebral perfusion. The infected aorta and endovascular stent-grafts were completely resected. Subsequently, we found an esophageal erosion $2 \mathrm{~cm}$ in length at the level of Th4 and Th5 with abscess, and the intrathoracic esophagus was divided just above the diaphragm and removed. After aggressive débridement (including resection of the phrenic and vagus nerves), we irrigated and cleaned the pleural cavity with warm normal saline solution.

Reconstruction of the extended aorta was conducted as we have previously described. ${ }^{3}$ In brief, a rifampicinsoaked Dacron polyester fabric graft (J Graft SHIELD NEO 26 mm; Junken Medical Co, Ltd, Chiba, Japan) was anastomosed to the normal ascending aorta. The arch vessels were reconstructed individually, systemic rewarming was initiated after reconstruction of the arch vessels, and perfusion of the heart and brain was reestablished through the side branch of the prosthetic graft. After systemic rewarming, the descending aorta was transected distally at the noninfected aorta, and the prosthetic graft was anastomosed to the true and false lumens. All intercostal arteries were ligated. The mobilized omentum was translocated into the thoracic cavity through a substernal diaphragmatic window, which covered the graft thoroughly (Figure 2, $A$ and $B$ ).

After closure of the chest, the patient was placed in a supine position. Through a left neck incision, the esophagus was brought out as a cervical esophagostomy, with the distal end stapled. A 2-cm incision was made in the left flank, and a 10F feeding tube was installed through a gastrostomy.

Three months after the operation, retrosternal gastric bypass was successfully performed. The patient showed no recurrence of infection without antibiotics at the 2-year follow-up.

\section{DISCUSSION}

Recently, several options for AEF repair after TEVAR have been described in the surgical literature. ${ }^{2}$ The primary concern of any surgical procedure for an AEF in an emergency situation is to control the bleeding. Reoperative TEVAR enables rapid control of bleeding and is less invasive than traditional surgery; however, reoperative TEVAR alone in this case would have left the infected endovascular stent-grafts, aortic wall, and esophageal defects untreated, increasing the risks of mediastinitis and sepsis. We believe that, because of the infectious nature of AEFs, endovascular treatment should only considered a bridging method. Definitive surgical treatment involving aggressive débridement (including resection of the esophagus, infected aortic wall, and endovascular stent-graft) and aortic reconstruction with a graft is the only effective method of saving serious infected patients with AEF after TEVAR, as was the case with our patient.

After resection of the infected native aorta, multiple combinations of treatment options have been used for aortic repair, such as in situ arterial reconstruction with an allograft, ${ }^{4}$ rifampicin-soaked Dacron polyester fabric graft, silvercoated graft, and extra-anatomic bypass. In our case, the native aorta showed extensive infection. In situ extended aortic replacement from the aortic arch to the middle descending aorta through a left posterolateral thoracotomy was therefore performed. ${ }^{3}$

In addition to repair of the aorta, the esophageal defect should be addressed. Treatment of the esophageal defect, to allow swallowing and avoid infectious complications, has been more problematic. Reardon and colleagues ${ }^{5}$ have suggested that small esophageal defects be treated by direct repair and larger esophageal defects or extensive esophageal wall necrosis be corrected by esophageal resection. When resection is necessary and reconstruction contemplated, cervical esophagostomy is recommended when possible to decrease the risk of intrathoracic sepsis in the event of anastomotic leakage. In our patient, a 2-cm esophageal defect with resultant mediastinal infection necessitated resection of the esophagus and cervical esophagostomy. In addition, use of an omental (or intercostal muscle) flap may reduce the risk of recurrent infectious complications.

\section{References}

1. Committee for Scientific Affairs, Sakata R, Fujii Y, Kuwano H. Thoracic and cardiovascular surgery in Japan during 2009: annual report by the Japanese Association for Thoracic Surgery. Gen Thorac Cardiovasc Surg. 2011;59:636-67.

2. Muradi A, Yamaguchi M, Kitagawa A, Nomura Y, Okada T, Okita Y, et al. Secondary aortoesophageal fistula after thoracic endovascular aortic repair for a huge aneurysm. Diagn Interv Radiol. 2013;19:81-4.

3. Hino Y, Okada K, Oka T, Inoue T, Tanaka A, Omura A, et al. Extended replacemen of the thoracic aorta. Eur J Cardiothorac Surg. 2013;43:176-81; discussion 181.

4. Vallabhajosyula P, Komlo C, Wallen T, Szeto WY. Two-stage surgical strategy for aortoesophageal fistula: emergent thoracic endovascular aortic repair followed by definitive open aortic and esophageal reconstruction. J Thorac Cardiovasc Surg. 2012;144:1266-8

5. Reardon MJ, Brewer RJ, LeMaire SA, Baldwin JC, Safi HJ. Surgical managemen of primary aortoesophageal fistula secondary to thoracic aneurysm. Ann Thorac Surg. 2000;69:967-70 